\title{
Fine-scale movement patterns of the sympatric Chilean and Peale's dolphins in the northern Patagonian fjords, Chile
}

\author{
Francisco A. Viddi ${ }^{1,2, *}$, Rob G. Harcourt ${ }^{1}$, Rodrigo Hucke-Gaete ${ }^{2,3}$, Iain C. Field ${ }^{1}$ \\ ${ }^{1}$ Graduate School of the Environment, Macquarie University, Sydney, New South Wales 2109, Australia \\ ${ }^{2}$ Centro Ballena Azul, c/o ICML, UACh, Casilla 567, Valdivia, Chile \\ ${ }^{3}$ Instituto de Ciencias Marinas y Limnológicas, Universidad Austral de Chile, Valdivia, Chile
}

\begin{abstract}
Animal movement is a central topic in ecology, as movements are crucial to habitat selection, foraging and spatial population ecology. Movement is a primary mechanism coupling animals to their environment, as organisms respond to environmental heterogeneity at different spatio-temporal scales. The fjord system in southern Chile is highly heterogeneous and sustains poorly known dolphin species, including the sympatric Chilean Cephalorhynchus eutropia and Peale's Lagenorhynchus australis dolphins. Focal dolphin group follows were undertaken between January and April 2007, 2008 and 2009 to assess the fine-scale movement patterns of these 2 species in southern Chile. Correlated random walk models (CRW) overpredicted dolphin paths for both species, indicating that dolphins displayed a resident type of movement. Only a small number of dolphin groups fitted a Lévy flight model, thus suggesting that dolphins undertake a non-random searching strategy. First-passage time (FPT) models for both species showed that dolphins spent a large proportion of their time in small localised areas of only $100 \mathrm{~m}$ radius. Generalized additive mixed models (GAMMs) demonstrated that Peale's dolphin movements were highly associated with kelp beds while Chilean dolphin movements were associated with rivers. Movement patterns of both species are very similar in scale and form, but they differ in relation to the associated ecological features. Movement models may be useful for developing holistic and more realistic predictions of how dolphins may respond to shifting resources as a consequence of environmental change with clear implications for conservation.
\end{abstract}

KEY WORDS: Cephalorhynchus eutropia - Lagenorhynchus australis - Dolphin movement · Correlated random walk · Lévy flight $\cdot$ First-time passage $\cdot$ Generalized additive mixed models

Resale or republication not permitted without written consent of the publisher

\section{INTRODUCTION}

Animals inhabiting a particular ecosystem are highly influenced by the degree of spatial heterogeneity, and this is reflected in animals' distribution patterns (Johnson et al. 1992b). However, the processes responsible for these patterns are linked to how organisms make use of their environment, either in search of food, mates or refuge against predators (Johnson 1980).

At the fine scale, distribution of animals results from the decisions that animals make to shape their movement patterns; these decisions have important consequences on their fitness (Prasad \& Borges 2006). Animals interact with their environment in complex ways at different spatial and temporal scales, and these interactions can produce varied movement patterns (Jonsen et al. 2003). How animals change their movement patterns in relation to the environment is a central topic in ecology (Turchin 1998), specifically regarding foraging, gene flow, dispersion, habitat selection, disease dispersal and spatial population ecology (Johnson et al. 1992b, Fryxell 
\& Lundberg 1998, Fauchald \& Tveraa 2003, Whitehead et al. 2008). Movement also plays an important function in the evolutionary history and evolutionary potential of a species (Bridle \& Hayes 2007), as evolution has favoured life strategies that can take advantage of changing mosaics of suitable habitats (Cain 1985). Understanding animal movement also has important implications for conservation, as identifying critical areas for populations is of great importance for management (James et al. 2005).

A major reason for animals to move is to locate food and, in particular, to find food patches that provide optimal rewards (Charnov 1976). However, animals tend to move only as much as they must to maximise their access to resources (Stevick et al. 2002). In response to spatial heterogeneity and resource patchiness, animals may vary their movement patterns by intensifying search effort in rich resource areas. Furthermore, animals need to make decisions about how much time is spent in any particular patch; therefore, time allocated to an area is likely to indicate the patch profitability (Fauchald \& Tveraa 2003). Accordingly, there is a trade-off between the departure from a food patch and the speed and likelihood of encountering a new one (Walsh 1996).

Many studies have demonstrated that animal movements and the time allocated to specific areas are correlated to environmental features and are shaped by differences in behaviour. The focus of these studies has been on understanding how dynamic variables, such as frontal systems, water currents, primary productivity, as well as fixed features, such as depth and topography, influence movement patterns. For instance, Suryan et al. (2006) found that foraging destinations, movement patterns and habitat use of short-tailed albatrosses Phoebastria albatrus were significantly associated with wind speed, bathymetry and chlorophyll concentration. Etnoyer et al. (2004) demonstrated that several species of sea turtles and blue whales Balaenoptera musculus spend considerable amounts of time off the Baja California peninsula in waters that exhibited high sea surface temperature gradients, indicative of frontal systems and therefore potential optimal foraging habitat.

The fjord region of southern Chile encompasses extremely heterogeneous marine ecosystems. It is also widely recognised as a highly productive area and a complex oceanographic system (Daneri et al. 2000). These complex conditions make the area a hotspot for marine species, including a high number of cetaceans (Hucke-Gaete et al. 2004, Viddi et al. 2010). Among these, Chilean dolphins Cephalorhynchus eutropia and Peale's dolphins Lageno- rhynchus australis seem to be the most frequently observed (Hucke-Gaete et al. 2006, Viddi et al. 2010). However, these 2 species are among the least studied of the dolphin family. They are coastal species restricted to the waters of Chile and Argentina. The Chilean dolphin, the only cetacean endemic to Chile, is distributed from Valparaiso $\left(33^{\circ} \mathrm{S}\right)$ to Cape Horn $\left(55^{\circ} \mathrm{S}\right)$, while Peale's dolphins range along the Chilean coast from Valparaiso $\left(33^{\circ} \mathrm{S}\right)$ southward to Tierra del Fuego and along the Argentinean coast northward up to San Matias Gulf $\left(38^{\circ} \mathrm{S}\right)$. This species is also found around the Falkland (Malvinas) Islands (Goodall 1994). While recent studies have focused on the distribution and habitat selection of these species (Heinrich 2006, Ribeiro et al. 2007, Viddi et al. 2010), little is known about fine-scale patterns of movement and their implications for habitat use.

The main objectives of this study were to assess the fine-scale movement patterns of Chilean and Peale's dolphins in northern Patagonian fjords, Chile, and to determine which environmental variables influence these patterns. To accomplish these objectives, a hierarchical framework approach of different models was used. (1) By using a correlated random walk model (CRW; Turchin 1998) we aimed to determine whether dolphins moved though the study area randomly, used the area in a persistent pattern (i.e. dolphins were residents) or used the area as a corridor. Deviations from this model can provide insights into the search strategy adopted by the dolphins within their home range. (2) By fitting Lévy flight models, we examined whether dolphin trajectories followed a deterministic or random movement search strategy (Viswanathan et al. 1999). Animal movement using Lévy flight models can provide important information about foraging strategies and the distribution of potential prey resources. (3) We used a first-passage time (FPT) model approach to determine the scale of searching behaviour and how much time dolphins allocated to specific areas, the so-called areas of restricted search (Fauchald \& Tveraa 2003). (4) Generalized additive mixed models (GAMMs) were used to assess which environmental features were related to the observed movement patterns.

\section{MATERIALS AND METHODS}

\section{Data collection}

Dolphin group follows (Altmann 1974, Mann 1999) were conducted between January and April in 2007 , 2008 and 2009 in the waters off Guaitecas Archipel- 
ago in southern Chile $\left(43^{\circ} 52^{\prime} \mathrm{S}, 73^{\circ} 45^{\prime} \mathrm{W}\right.$; Fig. 1). These follows were undertaken by 2 to 3 observers onboard a rigid hulled inflatable boat $5 \mathrm{~m}$ long. Observers searched for dolphins by naked eye and 7 $\times 50$ binoculars, covering a strip of $\sim 300 \mathrm{~m}$ on either side of the boat, at a searching speed of ca. 8 knots. Upon sighting a group of dolphins, search effort was interrupted in order to record dolphin geographical positions using a handheld GPS. Animals within a radius of $50 \mathrm{~m}$ were considered to be part of the same group. Dolphin group paths were generated by recording the location of the boat at 2 min intervals together with the distance to the dolphins (measured with a range finder) and angle with respect to magnetic north (using binoculars with a built-in compass). The corrected position of the dolphins was then derived by trigonometry and stored in ArcGIS 9.2, after correcting compass angles due to magnetic yearly variation. Lines connecting sequential movepoints, and consequent estimation of movement parameters, such as distance between moves and turning angles, were derived using Hawth's Analysis Tools for ArcGIS (Beyer 2004).

Dolphin follows were conducted as long as the group was in sight, while weather and light conditions permitted. Each sample session, and therefore each dolphin group encounter, for a given day was considered independent and became the unit for later analysis. Only groups that were followed for more than 30 min (Mann 1999) and did not react to the boat (e.g. bow-riding) were included in the analysis.

\section{Correlated random walk model}

For each group track, the observed net squared displacement was calculated, while distances and angles between successive locations were used to estimate the predicted net squared displacement using the CRW model of Kareiva \& Shigesada (1983):

$$
R_{\mathrm{n}}^{2}=\mathrm{n} m_{2}+2\left(m_{1}\right)^{2}\left(\frac{C}{c-1}\right)\left(\mathrm{n}-\frac{1-C^{\mathrm{n}}}{1-c}\right)
$$

where $R_{\mathrm{n}}^{2}$ is displacement (in $\mathrm{m}$ ) from the first location, $\mathrm{n}$ is the number of moves from the first location, $m_{1}$ is the mean move distance (in $m$ ), $m_{2}$ is the mean squared move distance (in $\mathrm{m}^{2}$ ), and $c$ is the mean of the cosines of the move angles (in degrees).

A CRW model measures the rate of change in area over time by incorporating move lengths (the measured distance from one location to the next) and turning angles (the change in angle from one location to the next) into a quantitative description of

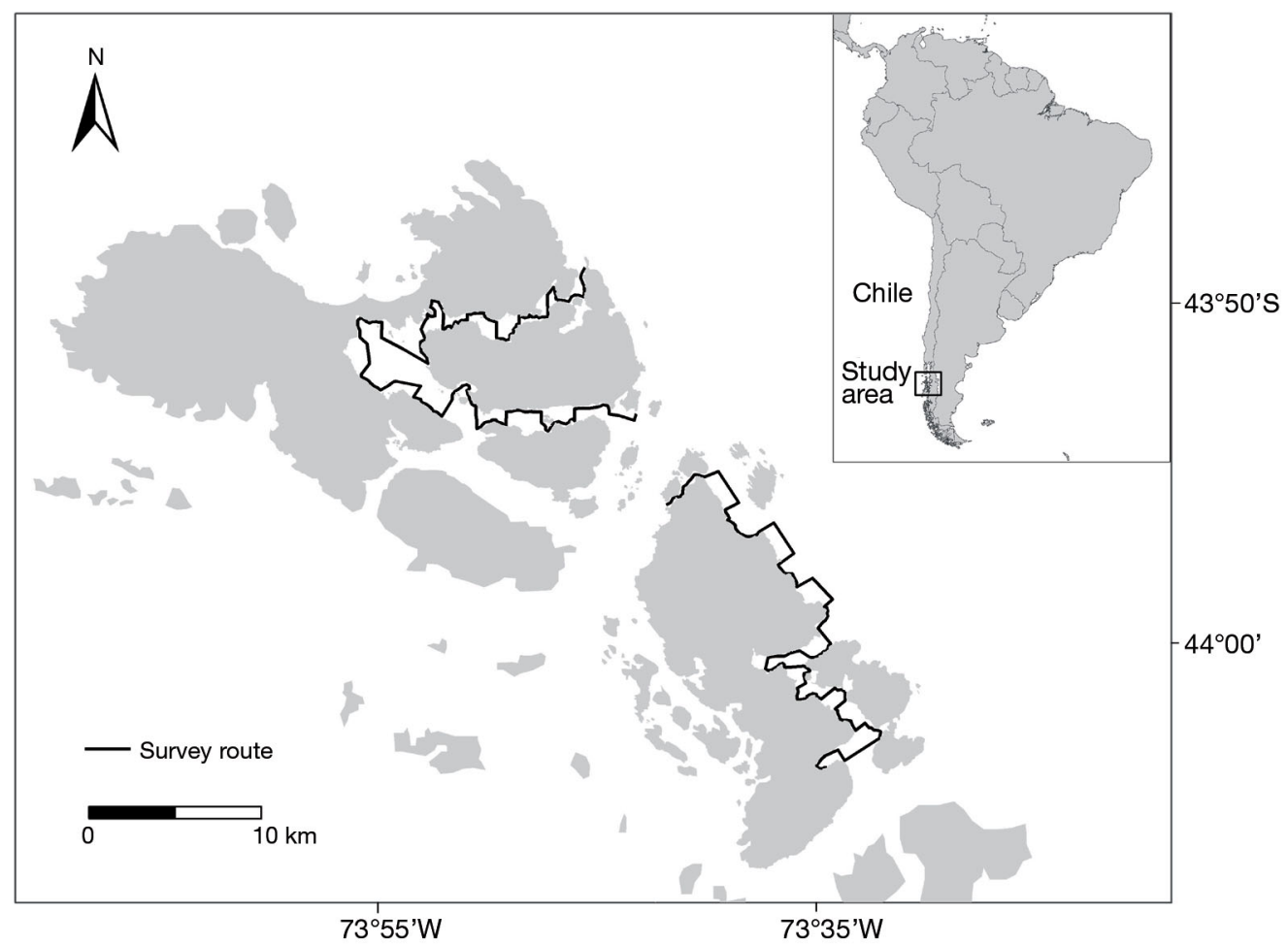

Fig. 1. The Guaitecas Archipelago of southern Chile. Survey routes used to locate Chilean and Peale's dolphins during summer (Jan-Apr) 2007-2009 
movement, or in our case, the dolphin group's trajectory (Turchin 1998).

The model assumes that there is no predisposition to turn in a preferential direction and that move lengths are not serially correlated. These assumptions were tested by calculating the autocorrelation function (ACF) and the Ljung-Box Q-statistic for all lags up to 6 moves for move length. Angular correlation was determined by defining sequential turns as left or right and performing a runs test to check for non-randomness (Turchin 1998). If any track exhibited significant autocorrelation for either of these parameters, then tracks were divided until autocorrelation in both turning angle and step length was no longer present. When dividing groups, if one subgroup became too short $(<30 \mathrm{~min})$ then it was discarded from the analysis.

Using the empirical distribution of move lengths and turning angles from all dolphin groups, an expected $R_{\mathrm{n}}^{2}$ was generated using a bootstrapped simulation of 1000 iterations with $95 \%$ CI determined by the percentile method (Turchin 1998). The observed and predicted net squared displacements were plotted over time to visualise how each dolphin group tracked fitted the CRW model. The tracks were then assigned a movement type based on whether more than $50 \%$ of the moves were within the $95 \%$ CI of the expected values for a CRW. Those groups that fit the model were termed 'correlated random walkers'. If a group's trajectories were smaller than that predicted by the CRW model, the group was then termed 'resident'. Conversely, if the observed trajectories were above the expected $R_{\mathrm{n}}^{2}$ then the dolphin group had greater displacement than predicted by the model and was therefore termed 'transient'.

\section{Lévy flight}

Lévy flights are a special class of random walks whose step lengths are not constant, but rather are chosen from a probability distribution with a powerlaw tail (Shlesinger et al. 1993). The distribution of move lengths, $\mathrm{N}(x)$, of each dolphin group, as well as pooled for each species, was assessed for whether they fit a Lévy flight model of the form (Viswanathan et al. 1999):

$$
\mathrm{N}(x) \sim x^{-\mu}
$$

where $x$ is the move-step length (in $\mathrm{m}$ ) between dolphin positions and $\mu$ is the power-law (Lévy) exponent $(1<\mu \leq 3)$. For each dolphin group and species, move lengths between successive locations were divided into 10 equal-range bins, and the frequency of move lengths in each bin was calculated. The Lévy parameter $\mu$ was estimated from a regression model of $\log$ frequency vs. log move length. Model fit was assessed by examining trends in the residuals.

\section{First-passage time model}

First-passage time model (FPT) is a quantitative estimate of the time required for an animal to cross a circle of a given radius (Johnson et al. 1992a). FPT was calculated at every location along the track of every dolphin group followed for radii ranging from 50 to $500 \mathrm{~m}$ by $50 \mathrm{~m}$ increments. Excluding the first and last legs of the paths, as FPTs backwards and forwards from these end positions are unknown, the log transformed FPT variance was then plotted against radii for each group followed to determine a peak in FPT variance. The variance peak identifies which spatial scale is best to differentiate high (area of restricted search, ARS) vs. low (transitory) passage times (Fauchald \& Tveraa 2003). The scale at which ARS was highest was then compared between species and used for assessment of which environmental variables were related to ARS. The scale was determined by estimating the average of the radius giving the highest relative variance for all trips pooled for each species.

\section{Dolphin movement and habitat association}

Generalized additive mixed models (GAMMs) were used to assess which environmental variables determined ARS in dolphins. GAMMs are an additive extension of GLMMs (generalized linear mixed models) in which part of the linear model predictor is specified in terms of smoothed functions of covariates (Lin \& Zhang 1999). This class of models allows flexible functional dependence of an outcome variable on covariates by using nonparametric regression, while accounting for correlation between observations by incorporating random effects.

To assess the environmental variables determining ARS, the values of FPT in each location along a dolphin track were used as the response variable. Since the response variable had a log-normal distribution, GAMM was used with a log link function. Dolphin group was included as a random effect, whereas distance to kelp Macrocystis pyrifera beds, distance to rivers, tide height and tide rate of change were 
included as fixed effects (explanatory variables) and were only retained if they significantly improved model fit. Akaike's information criteria (AIC) were used to identify the most parsimonious model. For competing models with a difference in $\mathrm{AIC}<2$, the model with the least number of parameters was selected (Lin \& Zhang 1999). All possible combinations of main effects and interactions were considered.

River mouths in the study area were digitised from satellite image composites using ArcGIS 9.2. Kelp beds were digitised, also using ArcGIS, from data taken in situ during low tide. Kelp beds were represented spatially by polygons generated from GPS locations at the edges of kelp beds. Only polygons $>300 \mathrm{~m}^{2}$ were included in the analysis to avoid overestimating the presence of kelp beds due to dispersed plants or small patches. These 2 map layers were then overlapped with dolphin movement locations to calculate the distance from each of these point locations to river mouths and kelp beds.

Tide height was extracted from the software WXTide32 version 4.7 (available at http://wxtide32. com), which gives complete tide tables with 1 minute accuracy. To account for water current during tidal cycle, a proxy of tide rate of change was calculated, which consisted of the proportion of change of tide height at $30 \mathrm{~min}$ intervals. Values close to 0 represented slack tide at high and low tide, whereas high positive and high negative values represented peak water current at flood tide and at ebb tide, respectively.

All statistical and modelling analyses were made using the statistical package $\mathrm{R}$ version 2.9.1. ( $\mathrm{R}$ Development Core Team 2009). Direct comparisons of time following dolphins, FPT radius and time within ARS between species were assessed using $t$ tests or the nonparametric equivalent, Wilcoxon rank tests. FPT was calculated using the $\mathrm{R}$ package adehabitat (Calenge 2006), while GAMMs were fitted in R using the package mgcv (Wood 2006).

\section{RESULTS}

\section{Survey effort and data summary}

Over the 3 fieldwork summer seasons a total of 54 surveys were conducted, which encompassed $290 \mathrm{~h}$ of effort searching for dolphins. Group follows were attempted for 173 dolphin groups which were encountered. However, only 90 groups were included in the analysis (those followed for $>30 \mathrm{~min}$ ), representing $95.9 \mathrm{~h}$ following dolphins. The mean $( \pm \mathrm{SE})$ duration of a group follow was $82.8 \pm 9.9 \mathrm{~min}$ (range $=30$ to $240 \mathrm{~min}$ ) for Chilean and $67.7 \pm 4.6 \mathrm{~min}$ (range $=30$ to $196 \mathrm{~min}$ ) for Peale's dolphins. Time following dolphins was not significantly different between species ( $t$-test; $t=-1.34, \mathrm{df}=34.5, \mathrm{p}=0.189)$. However, the number of dolphin groups sighted, time with dolphins and dolphin group size all varied between species (Table 1).

\section{Correlated random walk model}

Twelve tracks showed significant autocorrelation in either move length or turning angle. These tracks were subdivided into 3 paths, and at this scale, autocorrelation was no longer present. After subdivision, 35 paths were analysed for Chilean dolphins and 72 for Peale's dolphins.

Overall, CRW modelling for both species indicated that most groups showed a resident type of movement. For Chilean dolphins, $45.7 \%$ of the paths were classified as 'residents' and $63.9 \%$ for Peale's dolphins, indicating that individuals of both species remained closer to their initial location than would be expected if they were moving randomly. Chilean dolphin paths were consistent with assumptions of CRW models for $34.3 \%$ of the paths and therefore termed 'correlated random walkers', compared to only $11.1 \%$ for Peale's dolphins. Paths classified as 'transients' encompassed $20 \%$ and $25 \%$ of paths for Chilean and Peale's dolphins, respectively (Fig. 2)

Table 1. Cephalorhynchus eutropia and Lagenorhynchus australis. Survey data collected during focal follows of Chilean and Peale's dolphin groups in 3 consecutive summers off southern Chile

\begin{tabular}{|c|c|c|c|c|c|c|c|c|}
\hline \multirow[t]{2}{*}{ Year } & \multirow[t]{2}{*}{$\begin{array}{c}\text { No. of } \\
\text { surveys }\end{array}$} & \multirow[t]{2}{*}{$\begin{array}{l}\text { Search } \\
\text { effort (h) }\end{array}$} & \multicolumn{2}{|c|}{$\begin{array}{l}\text { No. of groups followed } \\
\text { (total detected) }\end{array}$} & \multicolumn{2}{|c|}{$\begin{array}{l}\text { Time spent with } \\
\text { dolphins (h) }\end{array}$} & \multicolumn{2}{|c|}{$\begin{array}{l}\text { Group size } \\
\text { (ind. group }^{-1} \text { ) }\end{array}$} \\
\hline & & & Chilean & Peale's & Chilean & Peale's & Chilean & Peale's \\
\hline 2007 & 23 & 118.6 & 9 (19) & 22 (38) & 12.3 & 25.6 & 5.1 & 6.2 \\
\hline 2008 & 26 & 142.3 & $16(24)$ & 36 (73) & 16.7 & 34.9 & 5.2 & 6.7 \\
\hline 2009 & 5 & 29.8 & $2(3)$ & 5 (16) & 2.5 & 3.9 & 3.2 & 4.3 \\
\hline Total & 54 & 290.7 & $27(46)$ & 63 (127) & 31.5 & 64.4 & 5.1 & 6.3 \\
\hline
\end{tabular}



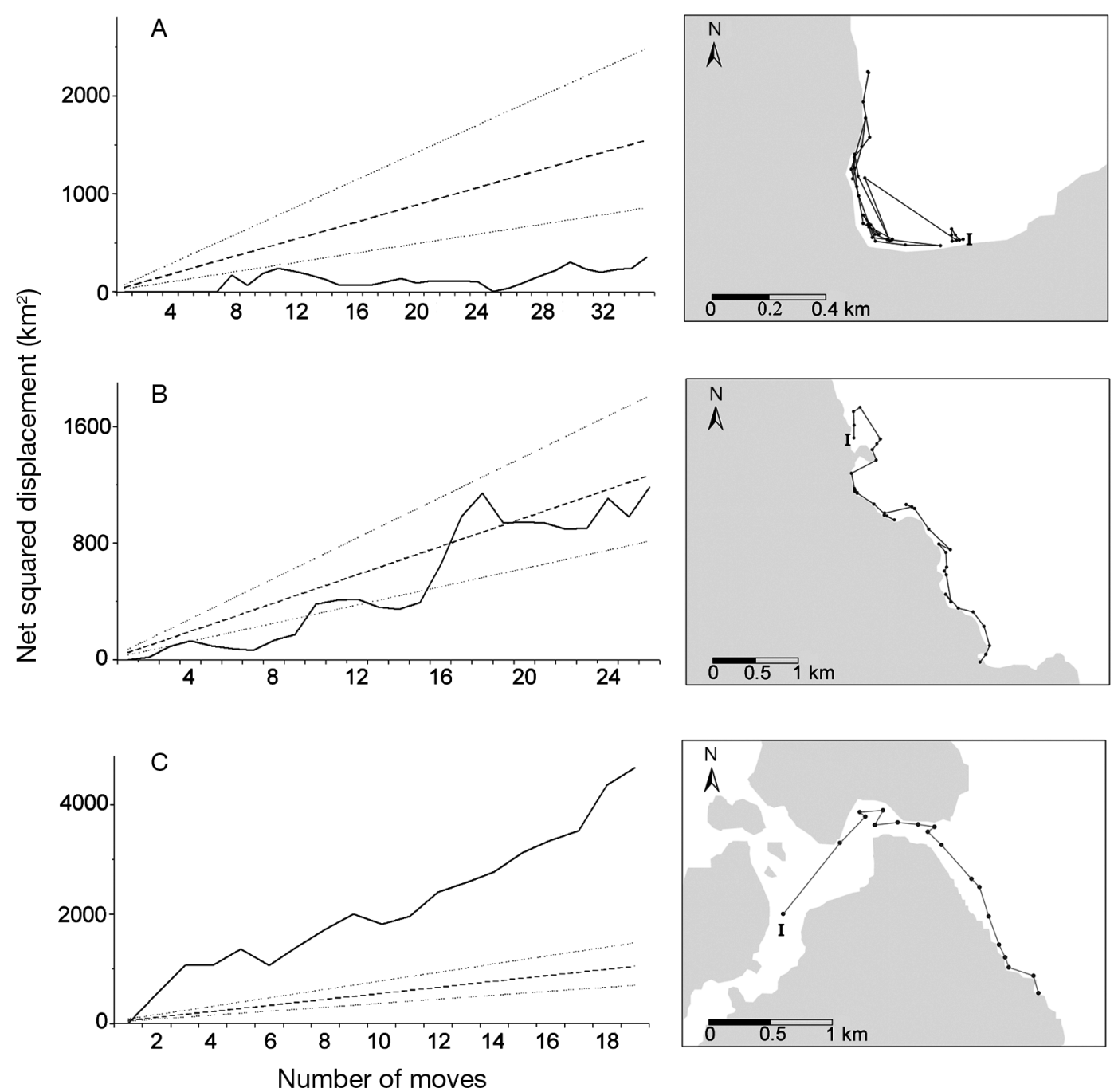

Fig. 2. Cephalorhynchus eutropia and Lagenorhynchus australis. Examples of observed (-) versus expected (---) net squared displacement and lower $25 \%$ and upper $95 \%(\cdots)$ CIs and corresponding trajectories plotted within the survey area for 3 dolphin groups demonstrating different movement types: (A) Chilean dolphin group ID9 classified as 'resident'; (B) Peale's dolphin group ID24 classified as 'correlated random walker'; and (C) Peale's dolphin group ID6 classified as 'transient'. I: beginning of trajectory

\section{Lévy flight}

The frequency distribution of move lengths of all trajectories pooled for each species resembled the distribution function of a Lévy flight model (Chilean: $\mu=1.94, r^{2}=0.734, p<0.001$; Peale's: $\mu=2.12, r^{2}=$ $0.76, p<0.001)$. However, when assessing each track separately, only 5 Chilean dolphin groups $(18.5 \%)$ and 10 Peale's dolphin groups (15.9\%) had frequency distributions of move lengths that fit the negative power of a Lévy flight.

Three of the Chilean groups that fit the Lévy flight model also fit a CRW model, while 2 were classified as 'residents'. From those Peale's groups that fit a
Lévy flight, only 1 group also fit the CRW model and 9 were deemed 'residents'. None of the dolphin groups classified as 'transients' fit the Lévy flight distribution model. Transient groups had a frequency distribution characterised by more long movelengths than short ones, resulting in a distribution with no descending right tail.

\section{First-passage time model}

Eleven Chilean dolphin groups $(40.7 \%)$ and 38 Peale's dolphin groups $(60.3 \%)$ showed clear peaks of variance in FPT. On average, ARS among all 
groups occurred within a $105 \mathrm{~m}$ radius for Chilean dolphins and $123 \mathrm{~m}$ radius for Peale's dolphins, a difference that was not significant ( $t$-test, $t=$ -0.833 , df $=19.8, \mathrm{p}=0.415)$. ARS for Chilean dolphins varied between 50 and $200 \mathrm{~m}$ radii, whereas for Peale's dolphins, the range was between 50 and $300 \mathrm{~m}$ radii. In contrast, the remaining number of groups for both species had relatively low FPT variance and no clear peaks, indicating that these dolphins did not concentrate their search effort in any particular area or scale along their paths during the observation period.

Chilean dolphins remained within their ARS for a median duration of $4.69 \mathrm{~min}$, ranging from 0.53 to 65.2 min, while Peale's dolphins remained within their ARS for a median duration of 4.15 min, ranging from 0.81 to $57.9 \mathrm{~min}$. The interspecific difference in the time that dolphins remained within their ARS was not significant (Wilcoxon rank-sum test, $\mathrm{W}=$ 685902.5, $\mathrm{p}=0.115)$.

\section{Dolphin movement and habitat association}

The median search radius for both species was $100 \mathrm{~m}$, and hence the values for FPT under this radius were used in GAMMs to determine association with habitat. The time that Chilean dolphins remained within their ARS was significantly associated with distance to rivers, distance to kelp beds and tide regime (Table 2). Dolphins that spent long times in their ARS (high values of FPT) were in general far from kelp beds (>4500 m), had movement distances $<500 \mathrm{~m}$ and were also $>3000 \mathrm{~m}$ from river mouths; time spent in ARS was also inversely related to tide height and generally positively related to tide rate of change (higher FPT values at flood tide; Fig. 3).

Table 2. Cephalorhynchus eutropia and Lagenorhynchus australis. Generalized additive mixed models (GAMMs) for first-passage time of Chilean and Peale's dolphins in relation to environmental variables. na: not available; edf: estimated degrees of freedom

\begin{tabular}{|c|c|c|c|c|c|c|}
\hline & \multicolumn{3}{|c|}{ Chilean dolphins } & \multicolumn{3}{|c|}{ Peale's dolphins } \\
\hline & Estimate & $t$ & $\mathrm{p}$ & Estimate & $t$ & $\mathrm{p}$ \\
\hline Intercept & 2.56 & 35.3 & $<0.001$ & 2.45 & 75.84 & $<0.001$ \\
\hline Smoother terms & edf & $F$ & $\mathrm{p}$ & edf & $F$ & $\mathrm{p}$ \\
\hline Distance to kelp beds & 7.80 & 3.59 & $<0.001$ & 4.82 & 9.74 & $<0.001$ \\
\hline Distance to rivers & 4.24 & 4.49 & 0.001 & 6.72 & 4.51 & $<0.001$ \\
\hline Tide height & 1.00 & 23.58 & $<0.001$ & 8.04 & 9.17 & $<0.001$ \\
\hline Tide rate of change & 7.58 & 7.27 & $<0.001$ & na & na & na \\
\hline
\end{tabular}

For Peale's dolphins, time spent in ARS was significantly associated with distance to rivers, distance to kelp beds and tide height (Table 2). In general, Peale's dolphins spent a longer time closer to kelp beds, farther from river mouths and at intermediate tide heights (Fig. 4).

\section{DISCUSSION}

This study is the first to comparatively assess the fine-scale movement patterns of Chilean and Peale's dolphins. In general, both species have a tendency to remain in the same locations, spend a great part of their time in small, localised areas and use movements that are influenced by specific conditions of the environment. Peale's dolphin movements are highly influenced by the presence of kelp beds while Chilean dolphin movements are shaped by proximity to river mouths.

The CRW model explained the movement behaviour of less than half of the dolphin groups. However, CRW model prediction provided a useful first step in describing and differentiating among types of movement for both species: (1) those dolphin groups that moved in a random fashion, the CRWs; (2) those whose moves were characterised by short return trips from a single place, the residents; and (3) those that undertook long distance movements, the transients. Nevertheless, most of the trajectories for both Chilean and Peale's dolphins were overpredicted by the model and therefore fell under the category of 'residents'. The lack of fit of Chilean and Peale's dolphin to CRW models suggests that these species do not undertake movement patterns typical of dispersal, but rather have a tendency to reside in the same locations. Theory predicts that movements characterised by CRW should increase the likelihood of successful dispersal (Zollner \& Lima 1999). The results for CRW models in this study gave first insights indicating a preference for particular habitat characteristics, probably to aid dolphins in finding food.

Overall for both species, $<20 \%$ of the dolphin groups fit a Lévy flight model, which indicates that other search tactics are involved and that prey items consumed by dolphins may not be randomly distributed at the scale at which this study was developed. Prey distribution and resources may be more predictable and may not respond as a function of 

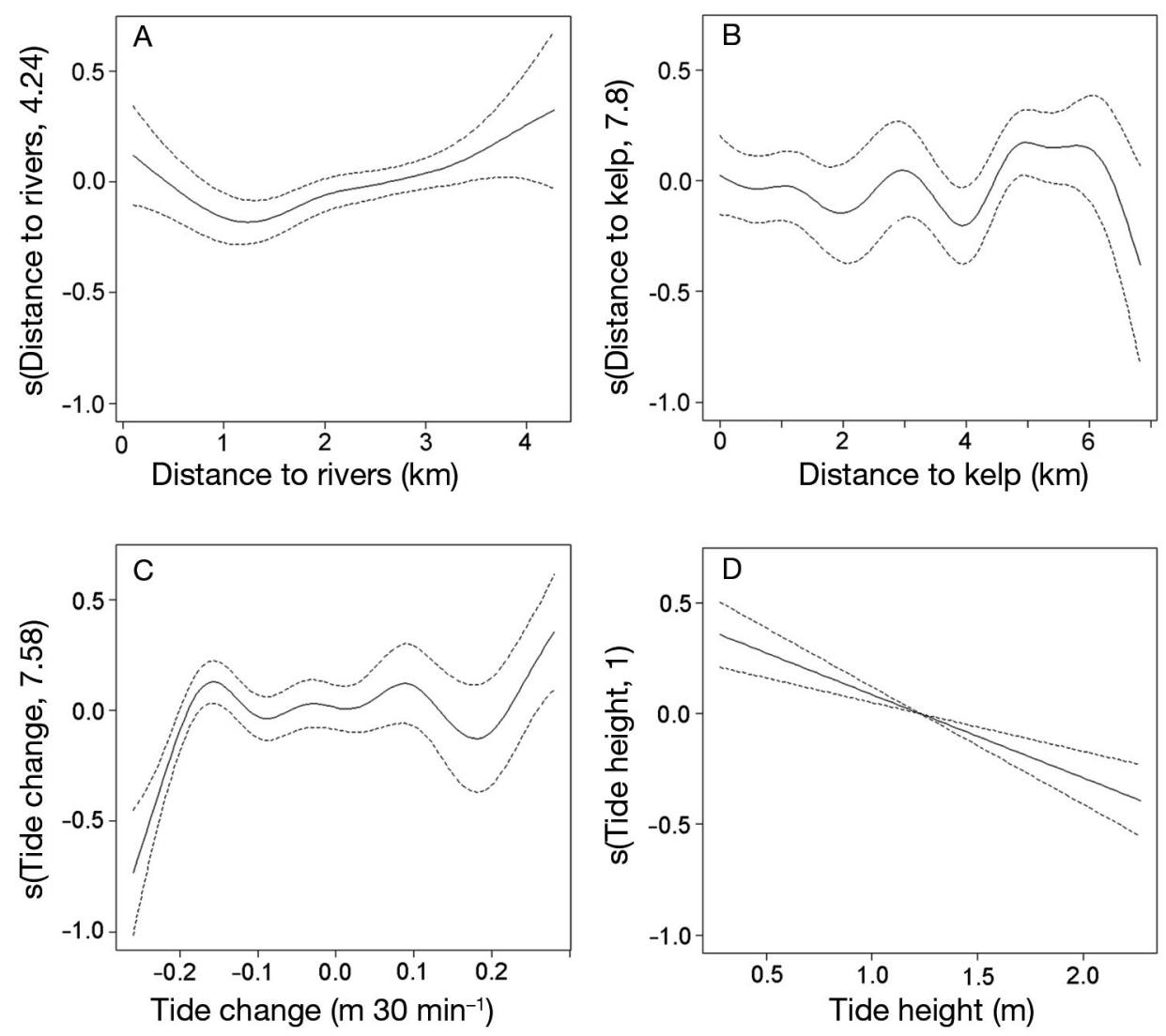

Fig. 3. Cephalorhynchus eutropia. Generalized additive mixed model (GAMM) function (-) and $95 \%$ CIs (---) of first-passage time (FPT) in relation to explanatory environmental variables for Chilean dolphins: (A) distance to rivers; (B) distance to kelp beds; (C) tide rate of change; and (D) tide height. Estimated degrees of freedom are in the parentheses on the $y$-axes

strict stochastic processes. A Lévy flight strategy implies that animals can visit more new and randomly distributed foraging sites than using a simple random walk under typical Brownian motion (Sims et al. 2008). For foragers, employing a Lévy flight search tactic would be more advantageous when resources are randomly and sparsely distributed, because the probability of revisiting previously visited sites is smaller than for a normal distribution (Viswanathan et al. 1996, Viswanathan et al. 1999, Ramos-Fernández et al. 2004, Sims et al. 2008). This specialised random walk model has super-diffusive properties comprising 'walk clusters' of short move step lengths with longer reorientation jumps between them (Sims et al. 2008). This pattern quickly takes the forager to more distant sites, reducing the likelihood that it will walk on its own steps again (Ramos-Fernández et al. 2004). Furthermore, this clustered pattern of step lengths is repeated across all scales, with the resultant scale-invariant clusters creating trajectories with fractal patterns (Bartumeus et al. 2005). A Lévy flight would then represent an optimal solution for searching complex landscapes (Viswanathan et al. 1996).

Lévy flight type of movement has been proposed to be widespread among a diverse range of marine organisms and has evolved in response to patchy resource distribution (Sims et al. 2008). However, this is clearly dependent on differences between individuals, populations, species, spatial and temporal scales and ecosystems that will shape the variations in movement strategies. The interpretation from the Lévy flight model in this study suggests that Chilean and Peale's dolphins movement patterns reflect finescale patterns on more predictable and on less scaleinvariant resources and are therefore more deterministic rather than probabilistic (i.e. 'blind'). Thus, these coastal species may have a complex mental map about resource locations; hence, the underlying resource landscape determines the distribution of move steps.

Thus, although spatial and environmental features influence movement (With et al. 1997), non-random search tactics such as those observed for Chilean and 
Peale's dolphins may also be influenced by intrinsic factors such as memory and social behaviour. These factors have been previously suggested to affect the movements of grey seals Halichoerus grypus (Austin et al. 2004), spider monkeys Ateles geoffroyi (Ramos-
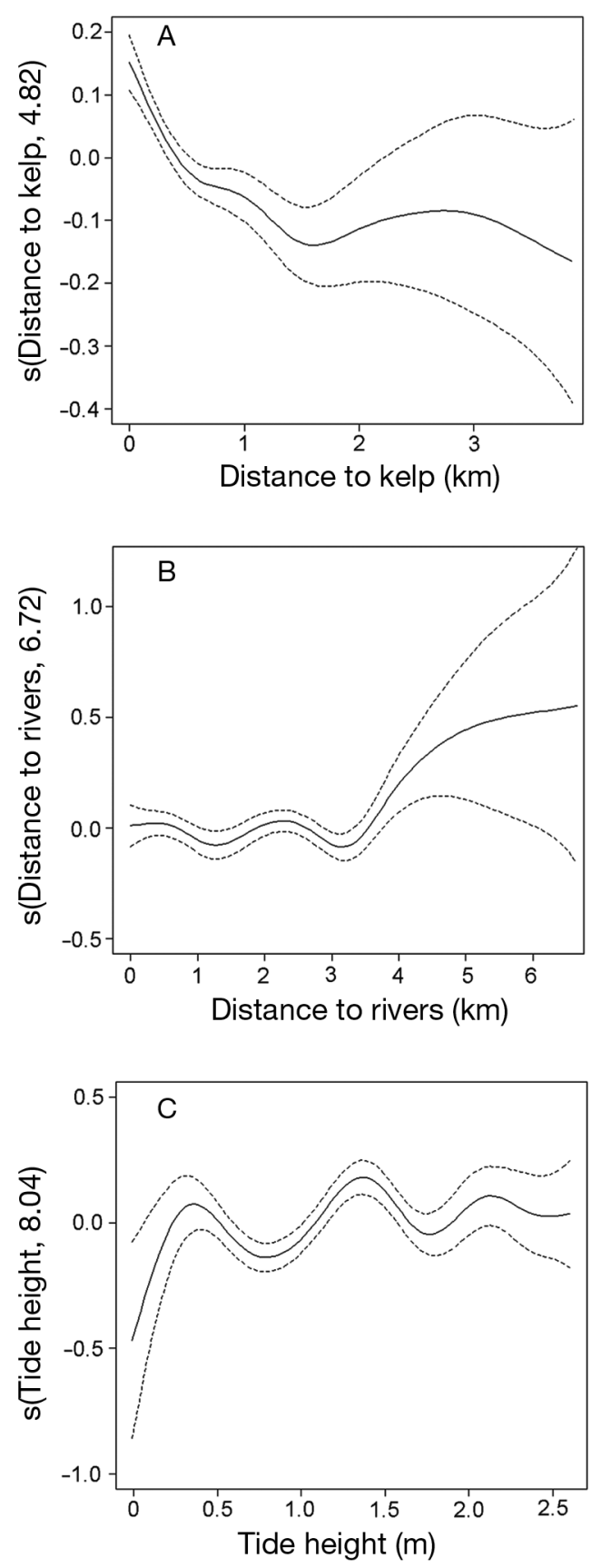

Fig. 4. Lagenorhynchus australis. Generalized additive mixed model (GAMM) function (-) and 95\% CIs (---) of first-passage time (FPT) in relation to explanatory environmental variables for Peale's dolphins: (A) distance to kelp beds; (B) distance to rivers; and (C) tide height. Estimated degrees of freedom are in the parentheses on the $y$-axes
Fernández et al. 2004) and baboons Papio hamadryas (Sigg \& Stolba 1981) and are also likely the case for dolphins given their high levels of sociability (Connor et al. 1998). Social behaviour is particularly important when considering the social influences on foraging vertebrates in relation to where, when, what and how they forage (Galef \& Giraldeau 2001).

Optimal foraging theory assumes that animals should attempt to minimise time spent between patches and maximise time within them (Pyke 1978). Predators need time to find prey patches, and the time spent searching is thought to be a function of patch characteristics (Stephens \& Krebs 1986). However, long distance travel should only be taken if there is a high chance of reward from the distant patch (Austin et al. 2004). An optimal foraging strategy would imply moves with low speed and high turning rates in areas of high prey density and high speed, straight moves between these dense areas, which is the so-called ARS strategy (Fauchald \& Tveraa 2003). Chilean and Peale's dolphins showed search activities confined to small ARS (radii $<130 \mathrm{~m}$ ) with high FPT in these small localised areas. The sites of concentrated search effort appeared to be foraging locations and may explain the dolphin's preference for these areas.

Just as observed by Bailey \& Thompson (2006), the results of the present study suggest that the small search radii could be a consequence of large, highly nutritional food being taken in this area, or alternatively, it may reflect the size of prey patches. Furthermore, the scale at which dolphins concentrate their movements may therefore be potential evidence that prey patches are clustered at these small scales, as proposed before for Antarctic petrels Thalassoica antarctica (Fauchald \& Tveraa 2003), bottlenose dolphins Tursiops truncatus (Bailey \& Thompson 2006) and short-tailed albatrosses (Suryan et al. 2006).

Many studies on marine organisms have shown that movement is strongly influenced by environmental features (Johnston et al. 2005, Phillips et al. 2006, Suryan et al. 2006). In the present study, FPT for Peale's dolphins was higher near kelp beds, far from rivers and at slack tide during high tide. Kelp beds are known to host a myriad of organisms, including species of fish and squid (Moreno \& Jara 1984), many of which may be fed upon by Peale's dolphins. Unfortunately, no data were available on which potential prey species are found in these kelp beds. These results provide further evidence on the importance of specific habitats for Peale's dolphins, an association previously documented in Argentinean waters (de Haro \& Iñiguez 1997) and in Chile 
(Lescrauwaet 1997, Viddi \& Lescrauwaet 2005, Viddi 2009). All these studies have suggested that the preference by Peale's dolphins for these habitats is highly related to finding food resources. Peale's dolphins are the only cetacean known to be highly associated with kelp beds (Viddi 2009). Certainly, other marine vegetated ecosystems are known to be important areas for food for other coastal dolphins, such as seagrass beds for bottlenose dolphins in Florida (Allen et al. 2001).

FPT for Chilean dolphins was higher close to rivers, far from kelp beds and associated with tide regime. Rivers and tide regime combined are suggested to be important to this species as they may represent hotspots of prey resources (Heinrich 2006, Ribeiro et al. 2007). In fact, rivers and estuaries have been identified as key features shaping habitat selection of several inshore cetacean species (Ingram \& Rogan 2002, Goetz et al. 2007). The interaction between freshwater run-off and tidal phases are also known to generate tidal fronts (Iriarte et al. 2007), which act as convergence zones and may concentrate plankton and weak swimming nekton (Mann \& Lazier 1991). These aggregations, in turn, result in localised patches of food for marine predators that feed on lower trophic levels (Wolanski \& Hamner 1988), such as dolphins and porpoises (Mendes et al. 2002, Johnston et al. 2005).

Overall, the results of this study illustrate that movement patterns of the sympatric Chilean and Peale's dolphins are very similar in scale and type. Main differences arise from the distinct ecological factors that shape dolphin movements, in particular, the associations with kelp beds for Peale's dolphins and rivers for Chilean dolphins. However, these results alone do not suggest strict habitat partitioning. Both species have been observed in mixed groups during travelling and feeding behaviours, yet this study does propose a specific preference for different habitats.

Animal movement models may be useful for developing more holistic and realistic approaches to predicting how animals may respond to shifting resources as a consequence of environmental change. The present findings provide important information for focused management efforts, and they highlight the importance of northern Patagonian fjords for coastal dolphin conservation. The coastal habits of these dolphins and their prevalence to concentrate in well-defined, small areas make them vulnerable to human activities such as fishing, vessel traffic, aquaculture, pollution and tourism, among others. Conservation of these dolphin species and their habitats could be achieved by incorporating habitat preference and movement pattern data into coastal management plans and regulations. In practice, areas covered by kelp beds and/or influenced by rivers must be taken into account when designing a conservation plan aimed at maintaining a healthy and functional ecosystem under a legal framework such as a Multiple Use Marine Protected Area (MUMPA). As 'flagship' species due to their emblematic significance, dolphins and other species such as the blue whale (Hucke-Gaete et al. 2004) can be used for their popularity to bring large marine areas into some degree of protection. Every effort made to conserve higher order predators and their ecosystems will also protect less emblematic species through an 'umbrella' species effect. This study provides an initial baseline on the importance of some specific areas of the Chilean coast to these 2 species based on their movement patterns and residency among patches. These areas could be among those in dire need of protection and have been included in a proposal to the Chilean Government (Hucke-Gaete et al. 2010).

The data presented here come from 3 restricted summer seasons only, so inferring similar findings about the ecological conditions and movement patterns of dolphins during other seasons through the year is not possible. Productivity of the area may fluctuate seasonally; thus, the data must be considered with caution for non-summer months. Future research over multiple years and covering all seasons should focus on long range dolphin movements, model replication into new areas, the environmental characteristics shaping movements and the implications for conservation.

Acknowledgements. Financial support was provided by the Rufford Small Grant Foundation, Wildlife Trust, Macquarie University Postgraduate Research Fund, Society for Marine Mammalogy and Tecnomar Chile. We are also thankful to all volunteers who assisted on the field. A. Ottensmeyer, R. Portner, J. Wiszniewski, A. McGregor and 3 anonymous reviewers provided valuable comments which improved earlier drafts of this manuscript. F.A.V. held the International Postgraduate Research Scholarship and the International Macquarie University Research Scholarship while undertaking $\mathrm{PhD}$ research at Macquarie University. The study was conducted with the approval of the Macquarie University Committee for the Care and Use of Animals in Research.

\section{LITERATURE CITED}

Allen MC, Read AJ, Gaudet J, Sayigh LS (2001) Fine-scale habitat selection of foraging bottlenose dolphins Tursiops truncatus near Clearwater, Florida. Mar Ecol Prog Ser 222:253-264 
Altmann J (1974) Observational study of behavior: sampling methods. Behaviour 49:227-267

- Austin D, Bowen WD, McMillan JI (2004) Intraspecific variation in movement patterns: modeling individual behaviour in a large marine predator. Oikos 105:15-30

Bailey H, Thompson P (2006) Quantitative analysis of bottlenose dolphin movement patterns and their relationship with foraging. J Anim Ecol 75:456-465

> Bartumeus F, da Luz MGE, Viswanathan GM, Catalan J (2005) Animal search strategies: a quantitative randomwalk analysis. Ecology 86:3078-3087

Beyer HL (2004) Hawth's analysis tools for ArcGIS. Accessed 12 July 2007. www.spatialecology.com/htools

Bridle JR, Vines TH (2007) Limits to evolution at range margins: When and why does adaptation fail? Trends Ecol Evol 22:140-147

Cain ML (1985) Random search by herbivorous insects: a simulation model. Ecology 66:876-888

Calenge C (2006) The package 'adehabitat' for the R software: a tool for the analysis of space and habitat use by animals. Ecol Model 197:516-519

Charnov EL (1976) Optimal foraging, the marginal value theorem. Theor Popul Biol 9:129-136

Connor RC, Mann J, Tyack PL, Whitehead H (1998) Social evolution in toothed whales. Trends Ecol Evol 13: $228-232$

> Daneri G, Dellarossa V, Quiñones R, Jacob B, Montero P, Ulloa A (2000) Primary production and community respiration in the Humboldt Current System off Chile and associated oceanic areas. Mar Ecol Prog Ser 197:41-49

de Haro JC, Iñiguez MA (1997) Ecology and behavior of the Peale's dolphin, Lagenorhynchus australis (Peale, 1848), at Cabo Virgenes $\left(52^{\circ} 30^{\prime} \mathrm{S}, 68^{\circ} 28^{\prime} \mathrm{W}\right)$, in Patagonia, Argentina. Rep Int Whali Comm 47:723-727

Etnoyer P, Canny D, Mate BR, Morgan L (2004) Persistent pelagic habitats in the Baja California to Bering Sea (B2B) ecoregion. Oceanography 17:90-101

> Fauchald P, Tveraa T (2003) Using first-passage time in the analysis of area-restricted search and habitat selection. Ecology 84:282-288

Fryxell JM, Lundberg P (1998) Individual behavior and community dynamics. Chapman \& Hall, London

Galef BG, Giraldeau LA (2001) Social influences on foraging in vertebrates: causal mechanisms and adaptive functions. Anim Behav 61:3-15

Goetz KT, Rugh DJ, Read AJ, Hobbs RC (2007) Habitat use in a marine ecosystem: beluga whales Delphinapterus leucas in Cook Inlet, Alaska. Mar Ecol Prog Ser 330: $247-256$

Goodall RNP (1994) Chilean dolphins Cephalorhynchus eutropia (Gray, 1846). In: Ridgway SH, Harrison SR (eds) Handbook of marine mammals, Vol 5. Academic Press, London, p 269-287

Heinrich S (2006) Ecology of Chilean dolphins and Peale's dolphins at Isla Chiloé, southern Chile. PhD thesis, University of St Andrews

Hucke-Gaete R, Osman LP, Moreno CA, Findlay KP, Ljungblad DK (2004) Discovery of a blue whale feeding and nursing ground in southern Chile. Proc R Soc Lond B 271: S170-S173

Hucke-Gaete R, Viddi FA, Bello M (2006). Marine conservation in southern Chile: the importance of the Chiloe-Corcovado region for blue whales, biological diversity and sustainable development. Centro Ballena Azul, Imprenta América, Valdivia
Hucke-Gaete R, Álvarez R, Navarro M, Ruiz J, Lo Moro P, Farías A (2010). Investigación para desarrollo de area marina costera protegida Chiloé-Palena-Guaitecas. Final Report. FNDR - BID TURISMO Cód. BIP No. 30040215-0, Gobierno Regional de Los Lagos \& CONAMA, Valdivia

Ingram SN, Rogan E (2002) Identifying critical areas and habitat preferences of bottlenose dolphins Tursiops truncatus. Mar Ecol Prog Ser 244:247-255

Iriarte JL, Gonzalez HE, Liu KK, Rivas C, Valenzuela C (2007) Spatial and temporal variability of chlorophyll and primary productivity in surface waters of southern Chile (41.5-43으. Estuar Coast Shelf Sci 74:471-480

James MC, Ottensmeyer CA, Myers RA (2005) Identification of high-use habitat and threats to leatherback sea turtles in northern waters: new directions for conservation. Ecol Lett 8:195-201

Johnson AR, Milne BT, Wiens JA (1992a) Diffusion in fractal landscapes: simulations and experimental studies of tenebrionid beetle movements. Ecology 73:1968-1983

> Johnson AR, Wiens JA, Milne BT, Crist TO (1992b) Animal movements and population dynamics in heterogeneous landscapes. Landscape Ecol 7:63-75

> Johnson DH (1980) The comparison of usage and availability measurements for evaluating resource preference. Ecology 61:65-71

Johnston DW, Westgate AJ, Read AJ (2005) Effects of finescale oceanographic features on the distribution and movements of harbour porpoises Phocoena phocoena in the Bay of Fundy. Mar Ecol Prog Ser 295:279-293

> Jonsen ID, Myers RA, Flemming JM (2003) Meta-analysis of animal movement using state-space models. Ecology 84 : 3055-3063

> Kareiva P, Shigesada N (1983) Analyzing insect movement as a correlated random walk. Oecologia 56:234-238

Lescrauwaet AK (1997) Notes on the behaviour and ecology of the Peale's dolphin, Lagenorhynchus australis, in the Strait of Magellan, Chile. Rep Int Whal Comm 47: $747-755$

Lin X, Zhang D (1999) Inference in generalized additive mixed models by using smoothing splines. J R Stat Soc B 61:381-400

> Mann J (1999) Behavioral sampling methods for cetacean: a review and critique. Mar Mamm Sci 15:102-122

Mann KH, Lazier JRN (1991) Dynamics of marine ecosystems, 1st edn. Blackwell, Malden, MA

Mendes S, Turrell W, Lütkebohle T, Thompson P (2002) Influence of the tidal cycle and a tidal intrusion front on the spatio-temporal distribution of coastal bottlenose dolphins. Mar Ecol Prog Ser 239:221-229

> Moreno CA, Jara HF (1984) Ecological studies on fish fauna associated with Macrocystis pyrifera belts in the south of Fueguian Islands, Chile. Mar Ecol Prog Ser 15:99-107

> Phillips RA, Silk JRD, Croxall JP, Afanasyev V (2006) Yearround distribution of white-chinned petrels from South Georgia: relationships with oceanography and fisheries. Biol Conserv 129:336-347

Prasad BRG, Borges RM (2006) Searching on patch networks using correlated random walks: space usage and optimal foraging predictions using Markov chain models. J Theor Biol 240:241-249

> Pyke GH (1978) Optimal foraging: movement patterns of bumblebees between inflorescences. Theor Popul Biol 13:72-97

R Development Core Team (2009) R: a language and environment for statistical computing. R Foundation for Statis- 
tical Computing, Vienna. Available at www.R-project.org Ramos-Fernández G, Mateos JL, Miramontes O, Cocho G, Larralde H, Ayala-Orozco B (2004) Lévy walk patterns in the foraging movements of spider monekys (Ateles geoffroyi). Behav Ecol Sociobiol 55:223-230

Ribeiro S, Viddi FA, Cordeiro JL, Freitas TRO (2007) Finescale habitat selection of Chilean dolphins (Cephalorhynchus eutropia): interactions with aquaculture activities in southern Chiloé Island, Chile. J Mar Biol Assoc UK 87:119-128

Shlesinger MF, Zaslavsky GM, Klafter J (1993) Strange kinetics. Nature 363:31-37

Sigg H, Stolba A (1981) Home range and daily march in a Hamadryas baboon troop. Folia Primatol 36:40-75

Sims DW, Southall EJ, Humphries NE, Hays GC and others (2008) Scaling laws of marine predator search behaviour. Nature 451:1098-1103

Stephens DW, Krebs JR (1986) Foraging theory. Princeton University Press, Princeton, NJ

Stevick PT, McConnell BJ, Hammond PS (2002) Patterns of movement. In: Hoelzel AR (ed) Marine mammal biology: an evolutionary approach. Blackwell Science, Oxford, p 185-216

Suryan RM, Sato F, Balogh GR, Hyrenbach KD, Sievert PR, Ozaki K (2006) Foraging destinations and marine habitat use of short-tailed albatrosses: a multi-scale approach using first-passage time analysis. Deep-Sea Res II 53: 370-386

Turchin P (1998) Quantitative analysis of movement: measuring and modeling population redistribution in animals and plants. Sinauer, Sunderland, MA

Viddi FA (2009) Behavioural ecology of small cetaceans in

Editorial responsibility: Michael Castellini,

Fairbanks, Alaska, USA the Northern Patagonian fjords, Chile. PhD thesis, Macquarie University

Viddi FA, Lescrauwaet AK (2005) Insights on habitat selection and behavioural patterns of Peale's dolphins (Lagenorhynchus australis) in the Strait of Magellan, southern Chile. Aquat Mamm 31:176-183

> Viddi FA, Hucke-Gaete R, Torres-Florez JP, Ribeiro S (2010) Spatial and seasonal variability in cetacean distribution in the fjords of northern Patagonia, Chile. ICES J Mar Sci 67:959-970

Viswanathan GM, Afanasyev V, Buldyrev SV, Murphy EJ, Prince PA, Stanley HE (1996) Lévy flight search patterns of wandering albatrosses. Nature 381:413-415

- Viswanathan GM, Buldyrev SV, Havlin S, da Luz MGE, Raposo EP, Stanley HE (1999) Optimizing the success of random searches. Nature 401:911-914

- Walsh PD (1996) Area-restricted search and the scale dependence of path quality discrimination. J Theor Biol 183:351-361

> Whitehead H, Coakes A, Jaquet N, Lusseau S (2008) Movements of sperm whales in the tropical Pacific. Mar Ecol Prog Ser 361:291-300

- With KA, Gardner RH, Turner MG (1997) Landscape connectivity and population distributions in heterogeneous environments. Oikos 78:151-169

Wolanski E, Hamner WM (1988) Topographically controlled fronts in the ocean and their biological influence. Science 241:177-181

Wood S (2006) Generalized additive models: an introduction with R. Chapman and Hall/CRC Press, Boca Raton, FL

Zollner PA, Lima SL (1999) Search strategies for landscapelevel interpatch movements. Ecology 80:1019-1030

Submitted: March 20, 2010; Accepted: June 9, 2011

Proofs received from author(s): August 19, 2011 